7. Reprod. Fert. (1973) 33, 239-244

\title{
A CHEMICAL PROCEDURE FOR EXTRACTION OF THE ACROSOMES OF MAMMALIAN SPERMATOZOA
}

\author{
M. H. BERNSTEIN AND R. J. TEICHMAN* \\ Department of Anatomy, Wayne State University, School of Medicine, \\ 540 E. Canfield, Detroit, Michigan 48201, U.S.A.
}

(Received 20th March 1972)

\begin{abstract}
Summary. Rabbit, human and bull spermatozoa treated with $9 \cdot 0$ mm-barbituric acid reveal elevation and rupture of the acrosomal membrane, as well as partial extraction of acrosomal material. Other sperm membranes do not appear to be affected. A subsequent detergent extraction (Triton X-100) solubilizes the remaining acrosomal material, membranes and associated structures. The action of barbituric acid on the acrosomes of the three types of spermatozoa is immediate, efficient and effective in low temperature ranges. The amount of protein extracted from spermatozoa was characteristic for each species examined. Major portions of protein were extracted with barbituric acid; the remaining acrosomal protein was obtained with the detergent. Enzymes identified in the extracts include acid phosphatase, $\beta$-glucuronidase, hyaluronidase and proteases, with acid, neutral and alkaline $\mathrm{pH}$ optima. The proteases were unique for each species.
\end{abstract}

\section{INTRODUCTION}

Removal of acrosomes of mammalian spermatozoa has been achieved in recent years with combinations of physical methods and chemical treatments. Hartree \& Srivastava (1965) introduced the use of a cationic detergent, Hyamine. Stambaugh \& Buckley (1969) used sonication and sucrose density-gradient centrifugation, as well as Hyamine. Subsequently, these authors (Stambaugh $\&$ Buckley, 1970) found that the addition of desoxycholate gave improved yields. Allison \& Hartree (1970) have recently presented an extensive study of acrosomal enzymes obtained with Hyamine. In all of these studies, the efficiency of acrosomal detachment does not exceed 50 to $60 \%$.

The action of Hyamine in this procedure has always been the least effective and most time-consuming step. We now report another chemical agent, barbituric acid (pyrimidine trione) that provides a more effective initial step in the detachment of acrosomes.

* Present address : Department of Anatomy and Reproductive Biology, School of Medicine, University of Hawaii. 


\section{MATERIALS AND METHODS}

\section{Sample preparation and extraction}

Semen samples were obtained from three sources: bull semen from the Michigan Animal Breeders Cooperative, East Lansing, Michigan, rabbit semen from Dutch and New Zealand breeders and human semen from donors. Bull and human samples were processed individually while rabbit samples were pooled to a volume of at least $1.0 \mathrm{ml}$. Sperm counts, semen volumes and motility estimations were recorded for each sample, and only fresh material of good quality was used.

Semen samples were diluted slowly with $20 \mathrm{ml}$ of cold $0.25 \mathrm{M}$-sucrose, gently stirred and centrifuged at $500 \mathrm{~g}$ for $10 \mathrm{~min}$. The washing procedure was repeated once for rabbit and twice for human and bull semen. All procedures were carried out at 0 to $4^{\circ} \mathrm{C}$.

Ten to $20 \mathrm{ml}$ of cold 9 mm-barbituric acid, $\mathrm{pH} 3 \cdot 2$, made up in $0.25 \mathrm{M}$ sucrose was added to the washed sperm pellets. The pellets were dispersed with a stirring rod and kept suspended for 20 min by gentle agitation in an ice bath. Following centrifugation at $8000 \mathrm{~g}$ for $10 \mathrm{~min}$, the supernatant was decanted for subsequent analysis.

Ten to $20 \mathrm{ml}$ of cold $0.1 \%$ Triton X-100 in $0.25 \mathrm{M}$-sucrose was added to the barbituric acid-treated sperm residue. The pellets were dispersed and centrifuged as above.

\section{Microscopy}

For light microscopy, samples of normal semen, washed spermatozoa and treated spermatozoa were agitated and fixed with $0.2 \%$ formaldehyde. Samples were removed and allowed to air dry on microscope slides, and stained with Giemsa (Hancock, 1952).

For electron microscopy, all samples were fixed in picric acid paraformaldehyde (Stefanini, Demartino \& Zamboni, 1967), post-fixed in 1\% osmium tetroxide, embedded in Vestopal $\mathrm{W}$ and stained with uranium and lead salts.

\section{Biochemical analysis}

Protein was determined according to the method described by Lowry, Rosebrough, Farr \& Randall (1951), acid phosphatase and $\beta$-glucuronidase by the methods of Straus (1956), and hyaluronidase and protease according to the method described by Glick (1963).

\section{RESULTS}

\section{Light microscopic examination}

In control samples of bull spermatozoa stained with Giemsa, the acrosome appears deep red, the equatorial segment pale red, the post-acrosomal segment pale blue and the mid-piece and tail deep red. In samples treated with barbituric acid for $15 \mathrm{sec}$ (Pl. 1, Fig. 1), anterior membrane elevation and acrosomal detachment were observed. Dense red masses became visible on the slide. With longer treatments of up to $60 \mathrm{sec}$, acrosomal detachment was progressive but, 
PLATE 1

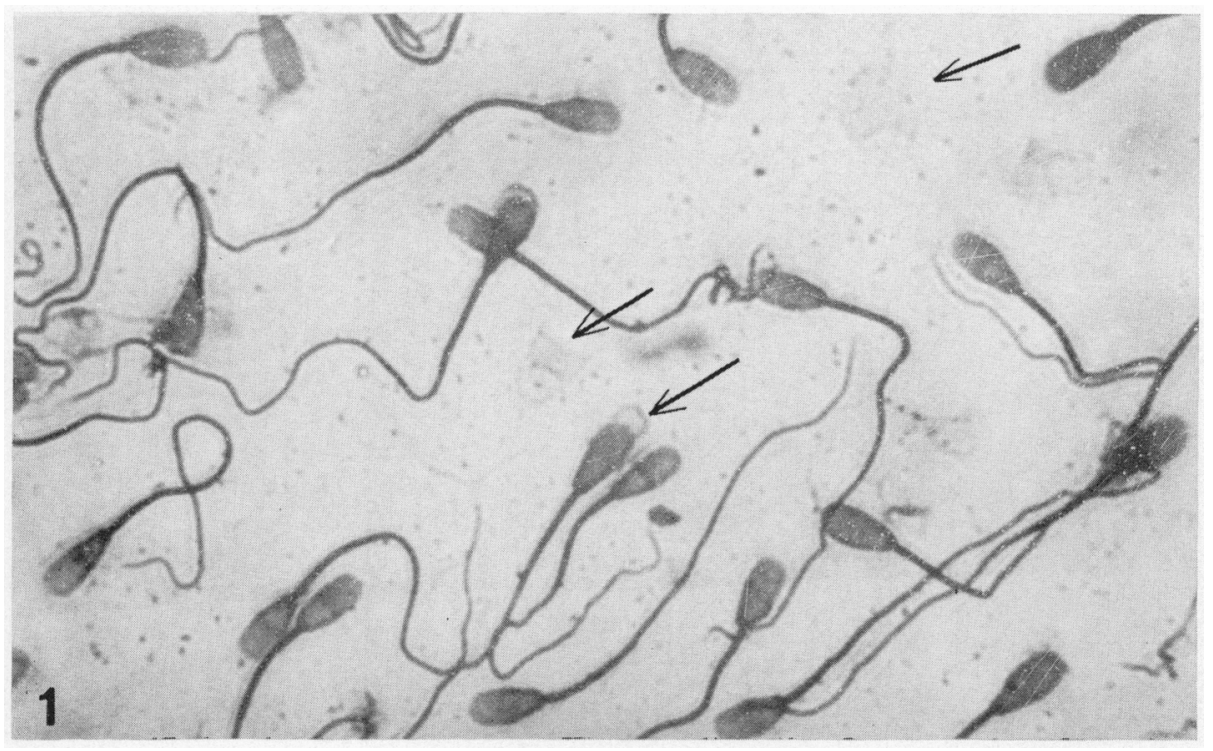

FIG. 1. Phase-contrast photomicrograph of a Giemsa-stained preparation of bull spermatozoa fixed after $15 \mathrm{sec}$ in $9 \mathrm{~mm}$-barbituric acid. The arrows indicate an elevated acrosome and acrosomes already free. Spermatozoa without acrosomes can be detected by the pale appearance of the anterior half of the head. 
at the same time, previously detached acrosomes were fragmented, solubilized and no longer visible.

\section{Electron microscopy observations}

Electron microscopic studies of normal spermatozoa were in conformity with the detailed results recently reported (Bernstein \& Teichman, 1972). Barbituric acid-treated spermatozoa (Pl. 2, Figs 2, 3 and 4) show dissolution of the homogeneous acrosomal cap substance and swelling of the acrosomal membranes. Even with the loss of the acrosomal material, inner and outer acrosomal membranes are discernible. The substance of the acrosomal collar is essentially unchanged and still exhibits tightly adherent membranes. The post-acrosomal material is somewhat swollen and membranous. The effects of barbituric acid appear to be limited to the head; the cell membrane remains visible around the midpiece and flagellum (Pl. 2, Figs 2 and 4).

Extractable protein was measured in six to ten semen samples for each species and average values were obtained. As seen in Table 1, substantial amounts of

Table 1. Protein levels in bull, human and rabbit spermatozoa treated with barbituric acid and Triton X-100

\begin{tabular}{l|c|c}
\hline \multirow{2}{*}{ Species } & \multicolumn{2}{|c}{ Protein $(p g /$ sperm.) } \\
\cline { 2 - 3 } & $\begin{array}{c}\text { Barbituric acid } \\
\text { alone }\end{array}$ & $\begin{array}{c}\text { Triton X-100 after } \\
\text { barbituric acid }\end{array}$ \\
\hline Bull & 4 & $0 \cdot 09$ \\
Man & 16 & $5 \cdot 0$ \\
Rabbit & 37 & $10 \cdot 0$ \\
\hline
\end{tabular}

Spermatozoa were washed in $0.25 \mathrm{M}$-sucrose; samples were derived from single ejaculates for human and bull and from pooled ejaculates for rabbit.

protein are available from rabbit and human spermatozoa with $80 \%$ of the total coming out in the initial extraction with barbituric acid. Bull spermatozoa yield much less protein, but more than $90 \%$ is obtained with the barbituric acid extraction.

\section{Acrosome extraction}

Following extraction of spermatozoa with barbituric acid, treatment with Triton X-100 (PI. 3, Figs 5, 6 and 7) completed removal of the acrosomal material and solubilized the remaining acrosomal and cell membranes though the homologue of the perforatorium, the equatorial bands of the rabbit spermatozoon, the acrosomal collar and the post-acrosomal material were still visible.

The bulk extractions were assayed for a variety of enzymes; oxidative enzymes were not detectable. Hydrolytic enzymes were present in the extracts, including acid phosphatase, $\beta$-glucuronidase and several proteases. There are species variations in the distribution of these enzymes in the extracted fractions; for 
example, it has been shown that acid phosphatase in rabbit and bull spermatozoa is not released until the detergent treatment (Teichman \& Bernstein, 1971). Proteases show a complex pattern involving either a multiplicity of enzymes or a pronounced pleomorphism. Characterization of the proteases by $\mathrm{pH}$ profiles (Teichman, 1969) shows species-specific patterns with both acid and alkaline optima as determined in the presence of urea.

Table 2. Enzyme activities in acrosomal extracts of bull, human and rabbit spermatozoa

\begin{tabular}{|c|c|c|c|c|c|c|}
\hline & \multicolumn{2}{|c|}{ Bull } & \multicolumn{2}{|c|}{ Man } & \multicolumn{2}{|c|}{ Rabbit } \\
\hline & $\begin{array}{c}\text { Barbituric } \\
\quad \text { acid }\end{array}$ & Triton & $\begin{array}{l}\text { Barbituric } \\
\quad \text { acid }\end{array}$ & Triton & $\begin{array}{l}\text { Barbituric } \\
\quad \text { acid }\end{array}$ & Triton \\
\hline $\begin{array}{l}\text { Acid phosphatase } \\
\beta \text {-glucuronidase } \\
\text { Hyaluronidase }\end{array}$ & $\frac{0.03}{1 \cdot 2}$ & $\begin{array}{l}3 \cdot 2 \\
2 \cdot 3 \\
-\end{array}$ & $\begin{array}{l}3 \cdot 7 \\
0 \cdot 15 \\
-\end{array}$ & $\begin{array}{r}13.8 \\
1.2 \\
-\end{array}$ & $\frac{0.03}{0.17}$ & $\begin{array}{c}0.47 \\
0.05 \\
-\end{array}$ \\
\hline $\begin{array}{c}\text { Proteolytic activity } \\
\text { (pH optima) } \\
3.5 \\
5 \cdot 0 \\
7 \cdot 0 \\
9 \cdot 0 \\
10 \cdot 0\end{array}$ & $\begin{array}{l}\bar{Z} \\
2 \cdot 0 \\
2 \cdot 0 \\
-\end{array}$ & $\begin{array}{l}\overline{-} \\
\overline{7 \cdot 0} \\
10 \cdot 0 \\
-\end{array}$ & $\begin{array}{l}0.6 \\
\frac{-}{0.3}\end{array}$ & $\begin{array}{l}2 \cdot 0 \\
- \\
- \\
-\end{array}$ & $\begin{array}{r}\overline{\overline{1}} \\
\overline{10 \cdot 0} \\
20 \cdot 0\end{array}$ & $\begin{array}{l}\overline{2 \cdot 0} \\
- \\
-\end{array}$ \\
\hline
\end{tabular}

Enzymes found in the acrosome extracts are reported as activity units. The units are defined as $\mu \mathrm{g}$ of product formed/ $\mu \mathrm{g}$ of protein/hr. Hyaluronidase is reported in Turbidity Reducing Units.

\section{DISCUSSION}

All procedures for the removal of acrosomes are empirical exercises for which there are as yet no reasonable concepts of mechanism. The action of barbituric acid (pyrimidine trione) on spermatozoa does appear to have some degree of specificity. The solutions are quite acid ( $\mathrm{pH} \mathrm{3.2)}$; however, equivalent acidities ( $\mathrm{pH} 3.2$ ) of hydrochloric and acetic acids were without effect on the structure of spermatozoa. All of these agents are lethal to spermatozoa.

Barbituric acid is presented as an improved first-step reagent in the detachment of mammalian acrosomes. This reagent is effective at low concentration and acts rapidly even at low temperature. This is in contrast to the prolonged incubation at elevated temperature required with Hyamine. Both barbituric acid and Hyamine remove large fragments of acrosomal material which is promptly solubilized after detachment from the sperm head. For complete extraction of acrosomal materials, a second-step treatment with detergent (Triton) is necessary with both barbituric acid and Hyamine. The detergent treatment alone is ineffective.

\section{EXPLANATION OF PLATE 2}

Figs 2, 3 and 4. The effects of 9 mm-barbituric acid on spermatozoa of rabbit (Fig. 2), man (Fig. 3) and bull (Fig. 4) are principally seen in the swelling and disruption of membranes (AcM) of the acrosomal cap region and a substantial loss of the acrosomal cap substance. The acrosomal collar (EqS) is not affected. Some swelling of the postacrosomal material (PAC) is also apparent. $\mathrm{ApB}=$ the homologue of the perforatorium. $\times 25,000$. 
PLATE 2

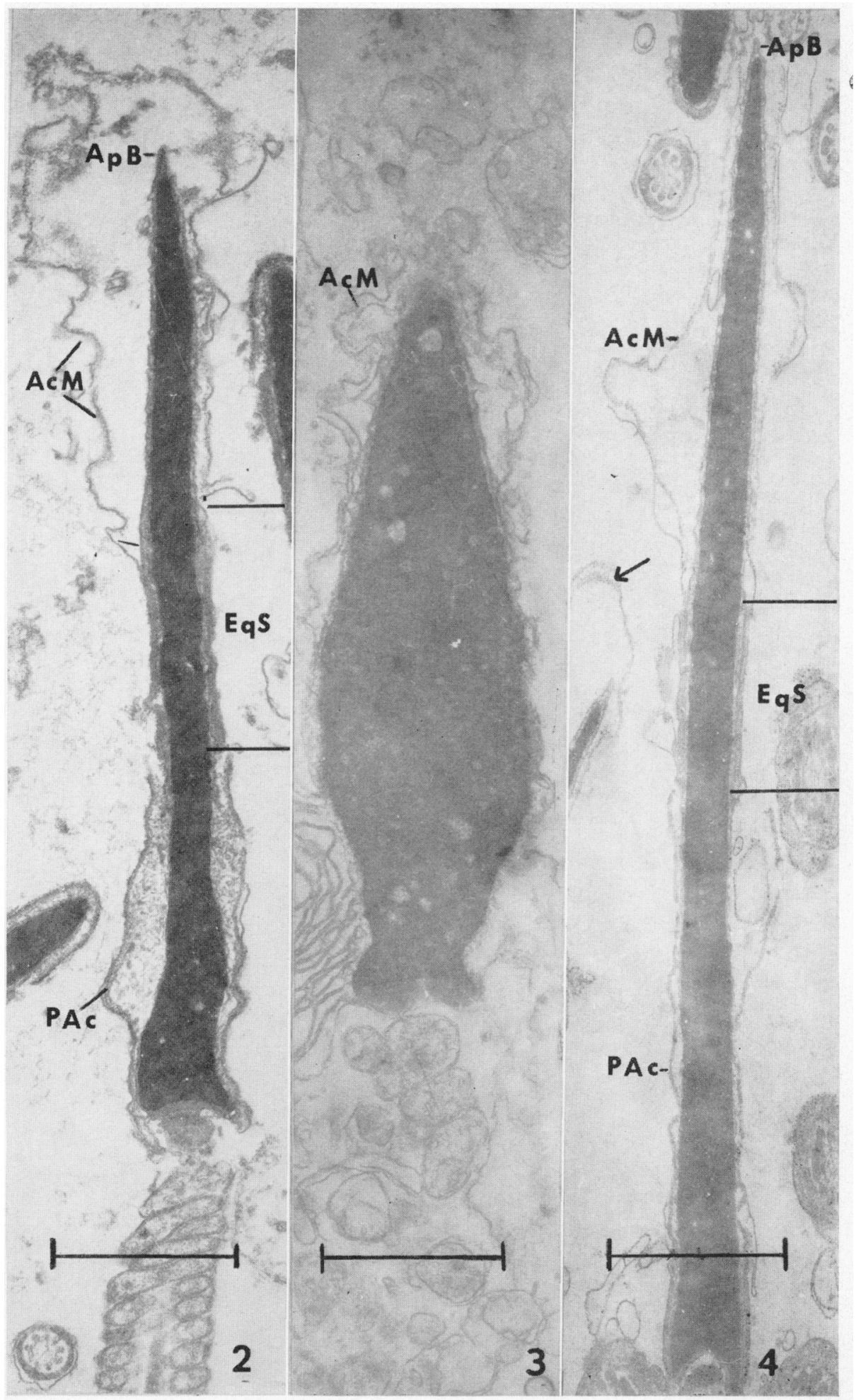


PLATE 3

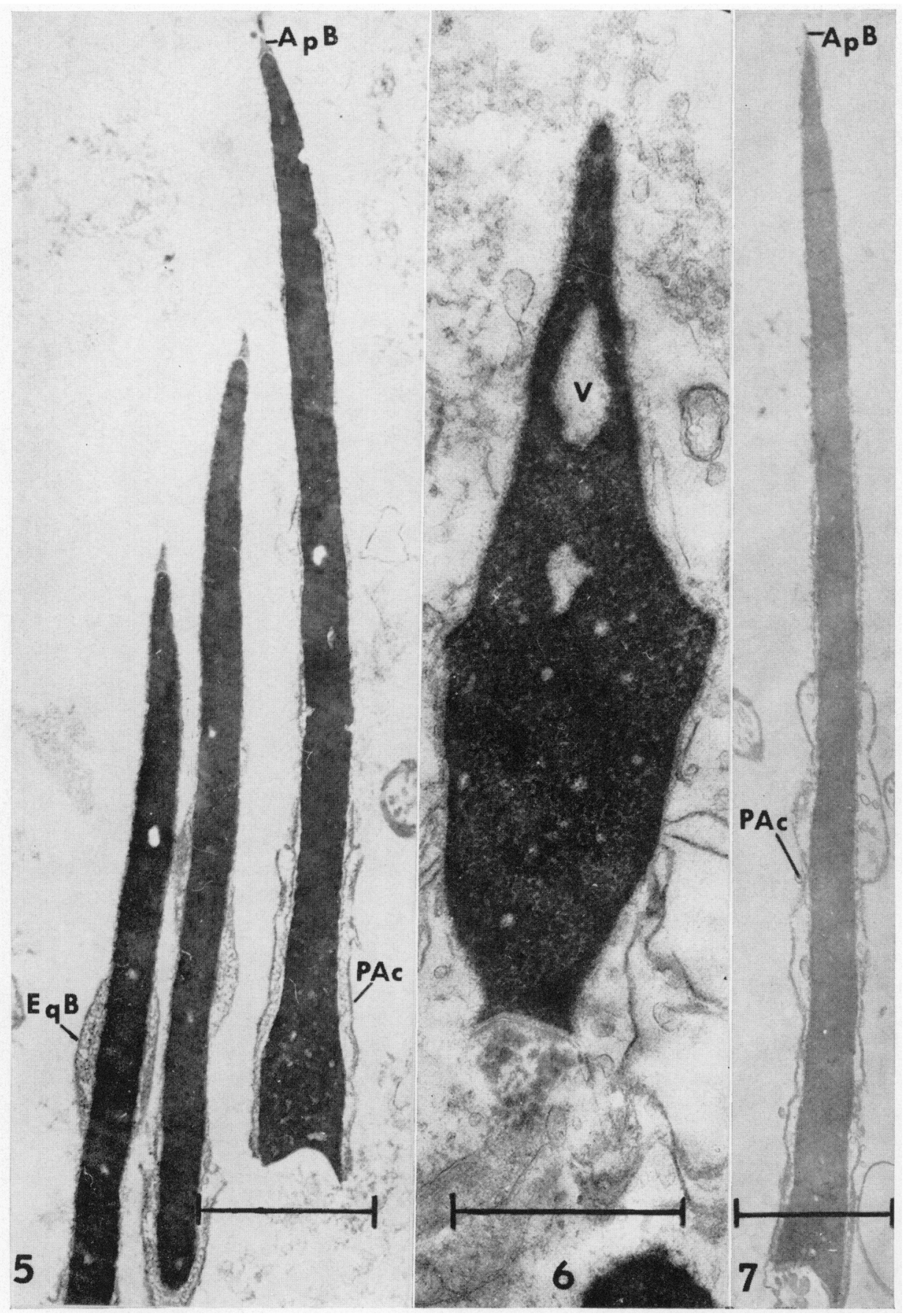

(Facing p. 243) 
The morphological observations are in accord with the chemical data, showing the need for the secondary detergent treatment to complete the extraction. The electron micrographs also provide strong support for considering the extracts to be essentially acrosomal. They also provide conclusive evidence for the lack of uniformity or homogeneity of the acrosome. In all the species studied, the acrosomal collar (Yanagimachi \& Noda, 1970) remains resistant to the extraction. The acrosomal cap substance shows considerable variation, both in ease of extraction and in the enzymes associated with this substance.

The analogy of the acrosome to a lysosome, or lysosome-like structure continues to be a widely held and attractive concept, based largely on a common Golgi origin and some shared staining charactistics. There are now a number of exceptions to the lysosome-like character of the acrosome, largely relating to the expectation of the presence of a number of hydrolytic enzymes with acid $\mathrm{pH}$ optima. The trypsin-like enzyme (Zaneveld, Srivastava \& Williams, 1969) obtained from acrosomal extracts shows a $\mathrm{pH}$ optimum of 8.0 to $8 \cdot 2$. Proteinases recently demonstrated by Yanagimachi \& Teichman (1972) have $\mathrm{pH}$ optima that range from acid to near neutral levels. Histochemical fine structure studies (Teichman \& Bernstein, 1971) have shown that acid phosphatase localizations (in bull and rabbit spermatozoa) are primarily subacrosomal and postacrosomal. Since acid phosphatase is probably the most widely utilized lysosome marker, this latter finding raises serious questions with regard to the 'lysosome-like' nature of the acrosome. The presence of enzymes with neutral and alkaline $\mathrm{pH}$ optima presents further difficulties, or . requires considerable expansion of the conceptual limits of the properties of structures that may be regarded as 'lysosome-like.'

The published data on hyaluronidase is highly equivocal. Washing of spermatozoa in 0.25 M-sucrose has been an integral part of this study after preliminary studies (Teichman, 1969) showed a marked reduction in protein levels in the washing fluids as compared to salt solutions. In spite of this precaution, it was not possible to specify whether hyaluronidase was a component of the spermatozoon or of the seminal plasma. Stambaugh \& Buckley (1969), working with a rabbit acrosome extract, have reported the recovery of hyaluronidase and a trypsin-like enzyme in a common complex. Zaneveld et al. (1969) have not observed hyaluronidase associated with a trypsin-like enzyme. The possibility that a number of acrosomal enzymes may exist in a single complex has recently been suggested (Yanagimachi \& Teichman, 1972). Most investigators are at least agreed that hyaluronidase is among the most labile

\section{EXPLANATION OF PLATE 3}

Figs 5, 6 and 7. Spermatozoa of rabbit (Fig. 5), man (Fig. 6) and bull (Fig. 7) treated with $0.1 \%$ Triton X-100 as well as with barbituric acid. Compared with Plate 2, there is a further loss of acrosomal material and a stripping of acrosomal membranes over the acrosome cap. Note the prominence and persistence of the homologue of the perforatorium (ApB) and the membrane investiture of the nucleus. In the rabbit spermatozoa (Fig. 5), the equatorial bulges $(\mathrm{EqB})$ are still present, although much of their substance has been leached. The nuclear vacuole (V) frequently seen in human spermatozoa (Fig. 6) appears to be unaltered by the treatment. The detergent appears to have relatively little effect on the post-acrosomal substance. $\times 27,000$. 
of spermatozoon-related enzymes, and is probably easily dislodged or inactivated in the process of washing semen samples. Loss in such a manner probably accounts for our inability to demonstrate hyaluronidase in human spermatozoa (Table 2).

Whatever the mechanism by which barbituric acid facilitates the detachment of acrosomes, a specific differentiation of the membranes over the acrosomal cap is demonstrated. Dissolution of the cell membrane is sharply reduced at the acrosomal collar (Pl. 3, Fig. 7). Buthala, Ericsson \& Chubb (1971) have recently shown a similar situation with inactivated Sendai virus attaching to the cell membrane of rabbit spermatozoa only over the acrosomal cap. The molecular basis for this phenomenon is not known.

\section{ACKNOWLEDGMENTS}

The work was supported in part by Grant No. HD-03416 from the Institute of Child Health and Human Development, National Institutes of Health, United States Public Health Service and by Grant No. GB-2542 from the National Science Foundation. It constituted a portion of a dissertation submitted by R.J.T. to the Graduate Division of Wayne State University in partial fulfilment of the requirements of the degree of Doctor of Philosophy.

\section{REFERENCES}

Allison, A. G. \& Hartree, E. F. (1970) Lysosomal enzymes in the acrosome and their possible rôle in fertilization. F. Reprod. Fert. 21, 501.

Bernstein, M. H. \& Teichman, R. J. (1972) Regional differentiation in the heads of spermatozoa of rabbit, man and bull. Am. F. Anat. 133, 165.

Buthala, D. A., Ericsson, R. J. \& Ghubb, G. T. (1971) Interaction of Sendai virus and rabbit sperm: transmission and scanning electron microscopy. Biol. Reprod. 5, 325.

GLıcK, D. (1963) Quantitative chemical techniques of histo- and cyto-chemistry, Vol. II, pp. 154, 202. Interscience, New York and London.

Hancock, J. L. (1952) The morphology of bull spermatozoa. 7. exp. Biol. 29, 445.

Hartree, E. F. \& SRIVAstava, P. N. (1965) Chemical composition of the acrosome of ram spermatozoa. 7. Reprod. Fert. 9, 47.

Lowry, O. H., Rosebrough, N. J., FarR, A. L. \& Randall, R. J. (1951) Protein measurement with the Folin phenol reagent. 7. biol. Chem. 193, 265.

Stambaugh, R. \& BuckLey, J. (1969) Identification and subcellular localization of the enzymes effecting penetration of the zona pellucida by rabbit spermatozoa. F. Reprod. Fert. 19, 423.

Stambaugh, R. \& Buckley, J. (1970) Gomparative studies of the acrosomal enzymes of rabbit, rhesus monkey and human spermatozoa. Biol. Reprod. 3, 275.

Stefanini, M., Demartino, G. \& Zamboni, L. (1967) Fixation of ejaculated spermatozoa for electron microscopy. Nature, Lond. 216, 173.

Straus, W. (1956) Concentration of acid phosphatase, ribonuclease, desoxyribonuclease, betaglucuronidase and cathepsin in 'droplets' isolated from kidney cells of normal rats. $\mathcal{F}$. biophys. biochem. Cytol. 2, 513.

Teichman, R. J. (1969) A cytochemical characterization of rabbit, human and bull acrosomes. $\mathrm{Ph} . \mathrm{D}$. thesis, Wayne State University, Detroit.

Teichman, R. J. \& Bernstein, M. H. (1971) Fine structure localizations of acid phosphatase in rabbit and bull sperm heads. $\mathcal{J}$. Reprod. Fert. 27, 243.

Yanagimachi, R. \& Noda, Y.D. (1970) Fine structure of the hamster sperm head. Am. F. Anat. 128, 367.

Yanagimachi, R. \& Tetchman, R. J. (1972) Cytochemical demonstration of acrosomal proteinase in mammalian and avian spermatozoa by a silver proteinate method. Biol. Reprod. 6, 87.

Zaneveld, L. J. D., SRivastava, P. N. \& Williams, W. L. (1969) Relationship of a trypsin-like enzyme in rabbit spermatozoa to capacitation. 7 . Reprod. Fert. 20, 337. 